\title{
ADDRM vindt voor het eerst online plaats
}

p 26 november 2020 vindt de 46e ADDRM plaats, de

Annual Dutch Diabetes Research Meeting. Deze jaarlijkse bijeenkomst wordt georganiseerd door de Nederlandse Vereniging voor Diabetes Onderzoek (NVDO) in samenwerking met de Nederlandse Associatie voor de Studie van Obesitas (NASO), de Netherlands Diabetes Epidemiology Study Group (NESDG), de Nederlands/Vlaamse werkgroep PsychoSociale Aspecten van Diabetes (PSAD) en de Vereniging voor Neurovasculaire Complicaties van Diabetes (NVCD). Door de huidige COVID-19-maatregelen zal de ADDRM van 2020 in een unieke online opzet georganiseerd worden. Bestuursleden Marten Engelse (hoofd laboratorium Eilandjes van Langerhans-isolatie en universitair docent aan het LUMC) en internist-endocrinoloog Helen Lutgers (Medisch Centrum Leeuwarden) kijken terug op de afgelopen jaren en de waarde van de ADDRM. Ook lichten zij alvast een tipje van de sluier op en vertellen over het programma van de online meeting.
Het samenbrengen van (basale) wetenschappers, artsen (kinderartsen, internisten en AIOS) en medisch psychologen die onderzoek doen naar diabetes mellitus of een speciale affiniteit hebben met diabetes mellitus; vanuit die gedachte is in 1974 de NVDO opgericht. En dat is nog altijd de leidende gedachte achter deze multidisciplinaire vereniging en achter de jaarlijkse meeting. 'En dat in een optimale sociale structuur', zegt Engelse 'Heel laagdrempelig, met veel tijd voor ontmoeting.' Lutgers beaamt dat. 'In 1988 mocht ik voor het eerst een poster presenteren tijdens de ADDRM. Ik was aangenaam verrast door het gezelschap. Er was geen gevoel van hiërarchie; de sprekers, deelnemers en sessies waren heel toegankelijk. Op grote congressen spreek je niet zomaar één van de kopstukken in de diabeteswereld aan. Hier wel, waardoor waardevolle ontmoetingen plaatsvinden tussen clinici en basale wetenschappers en interessante dwarsverbanden tot stand komen.'

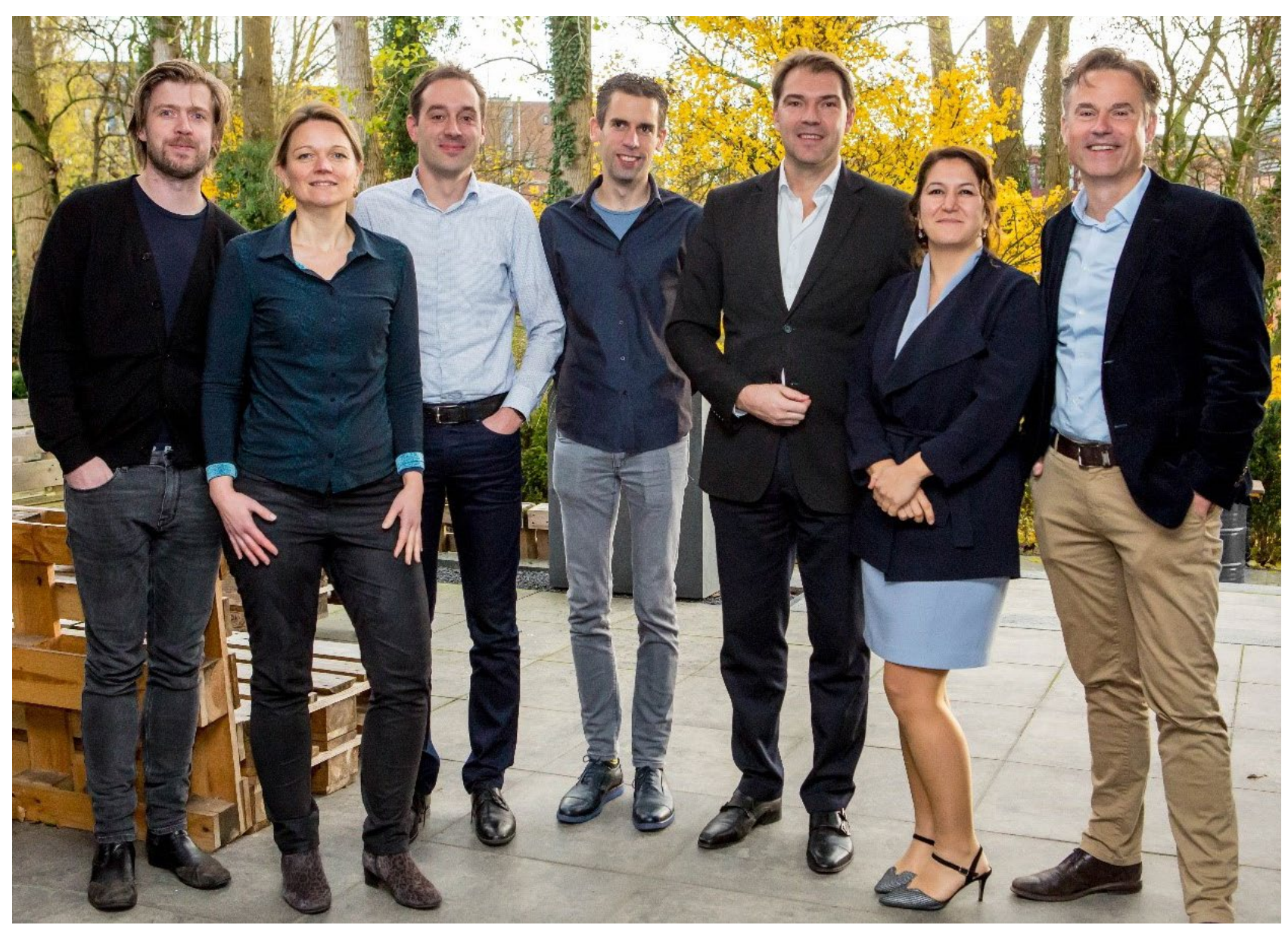

NVDO-bestuur

V.I.n.r. dr. ir. R. Stienstra, lid (Wageningen University/Radboudumc, Nijmegen), dr. H.L. Lutgers, penningmeester (Medisch Centrum Leeuwarden), dr. M.C.G.J. Brouwers, lid (Maastricht Universitair Medisch Centrum), dr. M. Brom, secretaris (Radboudumc, Nijmegen), dr. M.A. Engelse, voorzitter (Leids Universitair Medisch Centrum), B. Özcan, lid (Erasmus MC, Rotterdam) en dr. T. van Bemmel, lid (Gelre Ziekenhuis, Apeldoorn). 


\section{NIEUWE SAMENWERKINGSVERBANDEN}

Lutgers vertelt over een onderzoek dat een aantal jaren geleden werd gepresenteerd en waarvan de onderzoeksvraag heel relevant was, maar waarbij de uitgangspunten niet realistisch waren. 'Geen enkele diabetespatiënt blijft langdurig op een bloedglucosewaarde van $5 \mathrm{mmol} / \mathrm{l}$. Dat kun je in een laboratoriumsetting aanhouden, maar in de dagelijkse praktijk is dat onmogelijk. Deze onderzoeker en ik zijn gaan samenwerken: zij met haar ervaring vanuit het laboratorium en ik met mijn ervaring vanuit de klinische praktijk. Ik merk dat deze werelden vaak ver uit elkaar liggen en tijdens de ADDRM samenkomen.'

\section{NIEUWE KENNIS}

Ook nieuwe kennis opdoen is winst van de meeting. Nieuwe resultaten die door de wetenschappers worden gepresenteerd en waar andere wetenschappers hun voordeel mee kunnen doen. Of uitkomsten die ook meerwaarde hebben voor de klinische praktijk. Lutgers: 'We hebben jaarlijks ten minste twee internationale sprekers van naam, waarbij we ernaar streven dat hun lezingen voor zowel de basale wetenschappers als de clinici interessant zijn. Zo is bij mij een verhaal van een paar jaar geleden van een Zweedse toponderzoeker met nieuwe inzichten over de rol van bacteriële insulitis bij de ontwikkeling van type 1-diabetes erg bijgebleven. Om voldoende clinici naar de ADDRM te trekken voor de optimale interactie, hebben we ook altijd een parallelsymposium 'klinische diabetologie', waarbij actuele ontwikkelingen in de diabetespraktijk door nationale klinische diabetesexperts worden gebracht. Eigenlijk door diabetologen voor diabetologen, waarbij ik zie dat dit ook de onderlinge samenwerking tussen ziekenhuizen stimuleert.'

\section{VERBINDING VAN DIABETESONDERZOEK}

Ook voor Engelse als hoofd laboratorium zit de grote meerwaarde in het uitwisselen van kennis. 'Verbinding is het sleutelwoord. Verbinding van diabetesonderzoek in
Nederland. Jonge onderzoekers mogen hier voor het eerst een presentatie geven voor een kritisch publiek dat constructief meedenkt en feedback geeft. Dat is enorm leerzaam. En voor de oudere generatie zijn de in de loop der tijd ontstane netwerken van groot belang om samen te werken aan oplossingen of betere behandelmogelijkheden van alle facetten van diabetes. Basale en medische wetenschap komt hier samen. Het is alsof je samenwerkt met je buren of je collega's over de hele linie.'

\section{PROGRAMMA}

'Dit jaar moeten we het persoonlijke contact ontberen, maar desalniettemin hebben we een krachtig programma met goede keynote speakers', vervolgt Engelse. Het middagprogramma bestaat uit on demand presentaties van abstracts. Er is een chatmogelijkheid, zodat deelnemers en presentatoren van abstracts met elkaar in gesprek kunnen. Het avondprogramma is zo in elkaar gezet dat het voor iedereen interessant is. Er zijn twee discussietafels à la Jinek. Eén van de gespreksonderwerpen is Diabetes \& Technologie: wat doet diabetestechnologie met de mens? Keynote speakers behandelen onderwerpen als COVID \& Diabetes en COVID \& Obesitas. Ook worden net als voorgaande jaren twee prijzen uitgereikt. De dr. F. Gerritzenprijs wordt uitgereikt aan een recent gepromoveerde onderzoeker die klinisch onderzoek heeft gedaan op het gebied van diabetes mellitus. De Prof. dr. J. Terpstra Young Investigator Award wordt uitgereikt aan een jonge onderzoeker die onderzoek doet op het gebied van diabetes mellitus. Het winnende voorstel moet een briljant innovatief onderzoeksvoorstel zijn dat een heldere hypothese kent en zal leiden tot resultaten die relevant zijn voor - en toepasbaar in - het veld van onderzoek naar diabetes mellitus.

Engelse: 'Als bestuur streven we naar een hoogwaardige compact ADDRM met goede sprekers, inhoudelijke bijdragen en collegialiteit. We willen het publiek ook dit jaar weer een inspirerende meeting geven!' 